\title{
PEMBAHAGIAN PUSAKA ISLAM DAN PERMASALAHANNYA DI SINGAPURA (DISTRIBUTION OF MUSLIM'S ESTATE AND ISSUES IN SINGAPORE)
}

\author{
Feirul Maliq Intajalle \& Luqman Haji Abdullah \\ Jabatan Fiqh dan Usul, Akademi Pengajian Islam, \\ Universit of Malaya, Kuala Lumpur \\ (al_junied@yahoo.com.sg, luqmanabdullah@um.edu.my)
}

\begin{abstract}
Generally, the distribution of Muslims' estate in Singapore is based on the Administration of Muslim Law Act which is known as AMLA. This act has been enacted as a result of Muslims' experience under British occupation and the joining of Singapore to Malaysia. Although, this Act is part of the Personal Law for Muslims, there are still some issues in terms of legal application and Muslims' understanding of the Islamic law itself that affect the full implementation of the law in matters related to Muslims' estates in Singapore. This article is aimed at discussing these issues and to explore the real situation of distribution of Muslims' estates in Singapore.
\end{abstract}

Keywords: inheritance, Singapore, civil law, Islamic law

\section{Pengenalan}

Kedatangan agama Islam di rantau Asia Tenggara telah memainkan peranan yang banyak dalam mengubah kehidupan masyarakat Melayu. Malaysia dan Singapura berkongsi sejarah yang sama yang mana Islam bermazhabkan Shafii telah dibawa ke negara-negara ini oleh pedagang dan ulamak dari Arab dan India bermula pada abad keempat belas dan seterusnya tersebar luas sekitar semenanjung melalui pengaruh Kesultanan Melaka pada awal abad kelima belas (Hooker, 1983: 1-22; Abshire, 2011: 25, Rahimin Affandi, Ruzman, Nor Hayati \& Norafifah, 2013: 223-224, Wan Zailan, Ahmad Zuhdi \& Jasamad, 2013: 132-133).

Sewaktu Raffles tiba di Singapura pada tahun 1819 beliau mendapati penduduk di Singapura ketika itu adalah berbangsa Melayu yang dipercayai telah lama memeluk agama Islam (Tong, 2007: 49; Evans, 1927: 43; Shaharil Talib, 1995: 1-22, Maria, Rodney \& Hanafi, 2009: 41). Mereka merupakan nelayan yang 
mengamalkan sistem perundangan berpandukan kepada Undang-undang Adat Melayu di bawah pemerintahan Dato' Temenggong. Pulau tersebut mempunyai jumlah penduduk kurang dari 200 orang dengan Dato' Temenggong selaku pentadbir mewakili pemerintah Sultan Johor bagi mentadbir Pulau Singapura. Pemerintah Melayu ketika itu membuka kawasan pelabuhan bagi menarik perdagangan yang dapat menghasilkan cukai dan hadiah serta menarik perdagang dan orang asing bagi mempertingkat jumlah penduduk yang mana dapat menyumbang kepada harta dan kekayaan kerajaan masa itu (Lee, 2008: 1). Dengan kehadiran pihak British, tarikan perdagangan yang semakin luas memberi kesan kepada pertambahan penduduk yang beragama Islam dengan kemasukan perdagang-perdagang dari India, Arab dan sebagainya ke Singapura. Ini terbukti dengan pembentukan Kuarters bagi masyarakat Islam oleh pihak British sebagai penempatan bagi perdagang-perdagang Islam dari sememanjung Tanah Melayu, Jawa, Arab dan Hadramaut yang dikenali dengan perkampungan Kampong Glam (Perkins, 1984: 8; Hanizah, 1997: 71).

\section{Undang-undang Islam Singapura}

Agama Islam yang diterima di Singapura bukan sahaja dalam bentuk amalan harian semata-mata tetapi juga turut diterapkan dalam bentuk undang-undang tempatan. Perundangan Islam yang pertama dibentuk ialah Ordinan Perkahwinan 1880 yang dikenali sebagai Mahomedan Marriage Ordinance of 1880 sehingga diganti dengan Muslim Ordinance 1957. Pada bulan Ogos 1961, kedua-dua Perdana Menteri dari Persekutuan Tanah Melayu dan Singapura telah bersetuju untuk mengaplikasi Undang-undang Pentadbiran Hukum Islam yang dilaksanakan di dua bekas negeri-negeri selat iaitu di Melaka dan Pulau Pinang. Apabila perjanjian telah dipersetujui pada 16 September 1963, peruntukan ini telah dimasukkan di dalam Perlembagaan Singapura. Namun, Singapura telah keluar dari Persekutuan Tanah Melayu pada bulan Ogos 1965 sebelum terbentuknya Majlis Ugama Islam (Sharon Siddique, 1986: 315-326).

Kesan daripada perpisahan ini, Singapura sebagai salah sebuah negara sekular memberi penekanan yang tegas bahawa polisi negara tidak boleh bercampur aduk dengan keagamaan (Kong \& Yeoh, 2003: 77), dan ini telah dijadikan sebagai suatu amalan dan dasar perundangan di Singapura.

Walaubagaimanapun Kerajaan Singapura tetap memberi hak kebebasan kepada rakyatnya untuk mengakui, mengamalkan serta menyebarkan agama mereka sepertimana tertakluk dalam seksyen 15 perlembagaan negara. Selain itu juga, terdapat beberapa seksyen yang khusus bagi masyarakat Islam Singapura sepertimana termaktub dalam seksyen 152 Perlembagaan Singapura. Di dalam seksyen ini mengiktiraf masyarakat Melayu sebagai penduduk pribumi Singapura dan pemerintah harus mempromosikan perkara-perkara yang berhubungkait 
dengan masyarakat Melayu. Dalam hal ini juga, seksyen 153 menjelaskan bahawa pemerintah perlu membentuk badan Islam sebagai penasihat kepada presiden dalam hal yang berhubung kait dengan agama Islam (Bouma et. al., 2008: 99).

Selepas perpisahan dengan Malaysia, ramai masyarakat Islam pada masa itu, menuntut supaya diwujudkan sebuah badan yang dapat mengendalikan pentadbiran orang-orang Islam dengan dibentuk suatu perundangan khusus (Singh \& Wheatley, 1990: 629). Hasilnya, pada tanggal 13 Disember 1965, suatu rang Undang-undang Pentadbiran Hukum Islam telah dikemukakan di Parlimen Singapura oleh Menteri Kebudayaan dan Hal Ehwal Sosial Othman Wok. Pada 30 Disember pada tahun yang sama dibacakan buat kali kedua di parlimen dan satu jawatankuasa terpilih parlimen telah dibentuk untuk mengkaji rang undangundang tersebut dari setiap aspek dengan mengambil kira pendapat dan pandangan dari pemimpin-pemimpin Islam Singapura, wakil-wakil pertubuhan Islam dan juga pandangan dari individu-individu tertentu (Singapore Government, 1966: 1). ${ }^{1}$ Di dalam bacaan kedua ini, Othman Wok telah menjelaskan bahawa rang undang-undang hasil contoh yang diambil dari sebahagian perundangan pentadbiran Undang-undang Islam Selangor 1952 yang berkuatkuasa di beberapa negeri di Malaysia seperti Selangor, Negeri Sembilan, Pahang dan Perlis. Segala pandangan dan cadangan dari orang ramai telah dikaji dan dibincangkan oleh jawatankuasa terpilih dengan merumuskannya dan hasil laporannya telah dibentangkan di parlimen pada 31 Mei 1966 dan dibacakan kali ketiga pada 17 Ogos $1966 .{ }^{2}$

Dalam pembentangan Othman Wok kali ini, beliau menekankan bahawa rang undang-undang yang dikemukakan bukan Undang-undang Islam itu sendiri tetapi ia lebih melibatkan administrasi hukum Islam, menubuh sebuah Majlis Ugama Islam, mempertimbangkan untuk memberi kuasa eksekutif kepada majlis tersebut, menguatkan kuasa Mahkamah Syariah Singapura, had umur untuk berkahwin dan pembelaan bagi kaum wanita Islam Singapura. Pada akhirnya rang undang-undang tersebut telah diluluskan oleh Parlimen dan dikenali sebagai Akta Pentadbiran Hukum Islam atau singkatannya AMLA 'Administration of Muslim Law Act'. Akta ini mula berkuatkuasa dan menjadi sebuah undang-undang pada 25 Ogos 1966 (Sharon Siddique, 1986: 326) dan dua tahun kemudiannya iaitu tahun 1968 Majlis Ugama Islam Singapura mula tertubuh dan beroperasi (Ahmad Ibrahim, 1979: 47).

Jika diteliti perkara di dalam akta ini, Akta Pentadbiran Hukum Islam (AMLA) dapat dibahagikan kepada dua bentuk perundangan iaitu pengurusan hal ehwal keagamaan Islam serta kekeluargaan Islam yang turut melibatkan persoalan pembahagian pusaka bagi orang Islam.

Perundangan yang berhubungkait dengan hal ehwal keagamaan adalah pertama; Bidang kuasa Majlis Ugama Islan Singapura (MUIS), kedua; Pengurusan Masjid dan Sekolah Agama (Madrasah) di Singapura, ketiga; pengurusan sumber 
kewangan seperti Pengurusan wang Zakat, harta dan hartanah Waqaf, Nazar dan Wasiat, keempat; Sijil Halal dan Pengurusan Haji, dan kelima; Urusan Pendaftaran Kemasukan Agama Islam. Manakala perundangan yang berhubung kait dengan hal ehwal kekeluargaan Islam, pertama; Bidang kuasa Mahkamah Syariah, kedua; Perkahwinan dan Penceraian dan ketiga; Kehartaan.

Selain dari itu terdapat beberapa seksyen lain yang turut terkandung dalam akta ini seperti kedudukan Pendaftar, Kadi dan Naib Kadi sebagai kakitangan kerajaan, saksi dalam perbicaraan, bukti dalam perbicaraan, peraturan yang dikemukakan oleh kerajaan Singapura dan hukuman bagi kesalahan-kesalahan di bawah seksyen 129-140 AMLA.

\section{Pembahagian Harta Pusaka Islam dalam Perundangan Singapura}

Secara umumnya, pembahagian harta pusaka melalui kedua-dua perundangan ini mempunyai tujuan yang sama dalam menyelesaikan pembahagian kepada ahli keluarga yang terdekat "Immediate family" untuk menjaga kepentingan dan kebajikan ahli keluarga dalam meneruskan kehidupan mereka melalui kaedah yang telah ditetapkan dalam kedua-dua perundangan ini. Penetapan kaedah susunan iaitu senarai yang awal didahulukan merupakan suatu cara mengenalpasti individu-individu terawal yang layak mewarisi serta ahli keluarga yang bakal mengambil alih hak mewarisi agar harta-harta yang ditinggalkan dapat dimanfaatkan oleh kesemua ahli waris yang berhak dan saling bantumembantu sesama ahli keluarga.

Dalam menyelesaikan pusaka si mati adalah penting mengenal pasti sama ada si mati telah meninggal wasiat yang diiktiraf untuk menentukan status pusakanya samada pusakanya ditinggalkan wasiat (Testate) atau tanpa wasiat (Intestate). Dalam keadaan ada wasiat pusakanya akan dibahagikan mengikut ketetapan wasiat si mati (Sussman et. al, 1970: 16). Bagi kes tanpa wasiat secara umumnya dalam perundangan sivil, pembahagian pusaka akan dibahagikan kepada ahli waris berpandukan kepada urutan berikut iaitu didahulukan pasangan dan anak-anak si mati, diikuti dengan ibu bapa, adik-beradik dan anak saudara, datuk- dan nenek, dan terakhir, bapa saudara dan ibu saudara (Sussman et. al, 1970: 17).

Walaubagaimanapun dari segi pelaksanaannya amalan di setiap negara yang mengamalkan perundangan sivil adalah berbeza dari sudut teknikalitinya. Sebagai contoh, amalan di Singapura, sekiranya si mati meninggalkan pusaka tanpa wasiat pasangannya berhak mendapat setengah dari pusakanya dan baki setengah akan dikongsi oleh anak-anak. Bagi mereka di Malaysia, pasangan yang masih hidup hanya layak memperolehi sepertiga dari harta dan duapertiga akan dikongsi oleh anak. ${ }^{3}$ 
Dalam perundangan Islam, panduan khusus dalam mengenalpasti ahli waris serta bahagian-bahagian yang berhak diwarisi termaktub dalam sumber syariah yang utama iaitu al-Qur'an dan hadith dengan ahli waris yang utama adalah pasangan si mati, anak lelaki dan anak perempuan serta ayah dan ibunya. Selain dari itu telah ditetapkan ahli waris lain yang akan mewarisi sebahagian harta bagi menggantikan ahli waris utama yang tiada semasa pemergian si mati. Dalam penentuan bahagian yang berhak diwarisi, sebahagian ahli waris akan mewarisi melalui penentuan bahagian yang telah ditetapkan, sebahagian yang lain pula akan mewarisi setelah menolak bahagian-bahagian ahli waris yang lain. Sekiranya, bahagian yang dikongsi oleh lelaki dan wanita dalam kedudukan yang sama seperti anak lelaki dan anak perempuan, cucu lelaki dan cucu perempuan, lelaki akan memperoleh dua kali ganda dari bahagian wanita (Al-Sabuni, 1388H: 49, 65 \& 68), ia dilihat dari sudut peranan dan tanggungjawab kewangan yang lebih berat ke atas seorang lelaki (Abbas, Fadil Hassan \& 'Abbas, Sana' Hassan, 1991: 322), berbanding Undang-undang Sivil yang tidak membezakan status mereka disebabkan jantina.

Dalam peruntukkan Akta Pentadbiran Hukum Islam yang lebih dikenali sebagai 'Administration of Muslim Law Act' atau singkatannya AMLA Mahkamah Syariah mempunyai bidangkuasa untuk mengeluarkan sijil warisan bagi mereka yang bermohon sepertimana yang termaktub dalam seksyen 115 AMLA. Walaubagaimanapun segala tuntutan serta perbicaraan berkenaan harta pusaka hanya boleh dituntut dan dikemukakan di Mahkamah Sivil. Dalam satu kes tuntutan ke atas harta peninggalan iaitu Saniah Ali lwn Abdullah Ali, dimana Abdullah Ali menuntut haknya secara faraid daripada Saniah Ali selaku yang merupakan penama bagi wang Tabung Simpanan Pekerja atau lebih dikenali sebagai 'Central Providents Fund', Mahkamah Tinggi memutuskan bahawa jumlah wang di dalam CPF tidak tertakluk di bawah harta pusaka si mati dan tidak tertakluk di bawah seksyen 112(1) AMLA yang menyatakan,"(1) In the case of any Muslim person domiciled in Singapore dying intestate, the estate and effects shall be distributed according to the Muslim law as modified, where applicable, by Malay custom." Dengan itu, Plantiff iaitu Saniah Ali berhak ke atas kesemua wang yang dibayar oleh Badan CPF. Oleh kerana mahkamah yang membicarakan kes ini adalah mahkamah sivil maka keputusannya adalah berasaskan kepada perundangan sivil dan undang-undang pusaka Islam tidak diambil kira (Saniah Ali lwn Abdullah Ali [1990] SLR 584-593).

Mahkamah Syariah Singapura hanya mempunyai bidangkuasa dalam membicarakan kes-kes penceraian yang melibatkan pasangan yang beragama Islam dan hanya mengeluarkan sijil warisan bagi ahli waris yang memohon untuk pembahagian pusaka si mati sepertimana yang dinyatakan dalam seksyen 112 dan 115 AMLA. 


\section{Permasalahan Pembahagian Harta Pusaka Islam di Singapura}

Berdasarkan kajian-kajian lepas, permasalahan dalam pembahagian harta pusaka orang Islam di Singapura adalah isu yang telah wujud sekian lama di dalam pelbagai aspek terutamanya dalam pertembungan undang-undang antara sivil dan syariah. Dalam masa yang sama, terdapat beberapa permasalahan dalam instrumen syariah yang tidak diaplikasikan dengan cara yang sepatutnya antaranya pertembungan Undang-undang Sivil dan Hukum Islam, pengabaian fatwa oleh pihak Mahkamah Sivil, perancangan harta yang tidak kemas, kesedaran hukum pusaka Islam yang rendah.

\section{Pertembungan Undang-undang Sivil dan Hukum Islam}

Pertembungan undang-undang Sivil dan syariah bukan sesuatu isu yang baru dalam sesebuah negara. Ini kerana tidak semua perkara yang bersesuaian dengan syariat wujud dalam perundangan sivil khususnya melibatkan sesuatu yang berhubungkait dengan kehartaan. Harta-harta yang tertakluk di bawah perundangan sivil secara khusus tidak boleh dicabar atau dituntut oleh manamana perundangan atau pandangan hukum agama.

Jenis kehartaan yang dikawal di bawah perundangan khusus adalah pemilikan bersama (Joint Tenancy) untuk perumahan, Join Asset seperti wang simpanan bank dan polisi insurans dan penama (Nominee) untuk Wang Simpanan Pekerja Central Provident Fund (CPF) dan polisi insurans.

\section{Pemilikan Rumah secara 'Joint Tenancy'}

Sekiranya berlaku kematian ke atas pemilik harta dalam masalah 'Joint Tenancy'. Pemilik bersama yang masih hidup akan memiliki keseluruhan harta yang dikenali sebagai 'Right of Survivorship'. Tiada sebarang tuntutan boleh dibuat oleh mana-mana pihak untuk mewarisi harta tersebut. Ia merupakan prinsip undangundang dalam perkara yang melibatkan andaian 'Resulting Trust' dan andaian 'Advancement' (Halijah Mohamad, 2011: 97). ${ }^{4}$

Terdapat sebuah kes yang melibatkan ahli waris sekeluarga membuat tuntutan ke atas pusaka rumah privet yang dimiliki antara Al-Marhum dan Isterinya. Ke di antara Shafeeq bin Salim Talib E lain-lain lwn Fatimah Bte Abud bin Talib \& lain-lain. Plantif selaku Wasi (Executor) bagi pusaka Obeidillah bin Salim bin Talib menuntut agar pusaka rumah yang dimiliki bersama oleh defenden dengan si mati dibahagikan mengikut Undang-undang orang Islam sepertimana yang termaktub di dalam seksyen 112(1) AMLA. Namun, berdasarkan perundangan sivil rumah yang dikongsi berdasarkan kontrak 'Joint Tenancy' tidak lagi dianggap sebagai salah satu daripada pusaka bagi si mati. Turut 
dikemukakan semasa perbicaraan, fatwa yang dikemukakan oleh Jawatankuasa Fatwa bahawa harta sebegini diambilkira sebagai harta sepenceraian antara si mati dan isterinya ke atas harta yang dimiliki bersama. Dengan itu, setengah dari pusaka tersebut perlu dibahagikan secara faraid. Berdasarkan kepada keterangan dan bukti yang dijelaskan di Mahkamah Tinggi, Mahkamah dapati tiada sebarang ketetapan dalam AMLA atau perundangan lain yang mencadangkan agar 'Common law' dalam masalah pemilikan 'Joint Tenancy' tidak boleh diaplikasikan ke atas orang Islam. Atas dasar itu, mahkamah memutuskan bahawa defenden berhak secara keseluruhannya ke atas rumah yang dimiliki secara bersama yang mana defenden merupakan satu-satunya pemilik bersama yang masih hidup. Dengan ini, plantif telah gagal dalam permohonannya dan dikenakan bayaran kos mahkamah. Pada tahun berikut, kes ini dirayu kembali dan berakhir dengan rayuannya ditolak juga kerana keterangan yang dikemukakan tidak kukuh (Shafeeq bin Salim Talib \& Anor lwn Fatimah Bte Abud bin Talib \& Anor [2009] 3 SLR 439-451; [2010] 2 SLR 1123-1153)..

Melalui perbahasan kedua-dua kes di atas mendapati kontrak 'Joint Tenancy' mempunyai kesan kepada jumlah hak yang dimiliki dan perpindahan secara automatik yang berlaku sekiranya berlaku kematian ke atas salah seorang dari pemilik. Dengan pemindahan secara automatik apabila berlakunya kematian mengakibatkan pertembungan kepada fatwa yang menjelaskan bahawa $50 \%$ dari hak milik rumah tersebut perlu dibahagikan mengikut faraid dan bukan pemilikan mutlak bagi pemilik yang hidup (Majlis Ugama Islam Singapura, 1991: 38).

Sadali Rasban ${ }^{5}$ (2010: 21-21) berpandangan bahawa fatwa berkenaan hak milik rumah secara 'Joint Tenancy' tidak seharusnya bertentangan dengan konsep perundangan 'Joint Tenancy' yang memberikan hak mutlak kepada pemilik yang masih hidup sekiranya berlaku kematian ke atas salah seorang dari pemilik. Fatwa yang membahagikan hak 50:50 telah meninggalkan kemudaratan kepada ahli waris terdekat terutamanya Isteri dan anak-anak si mati. Ketatapan setengah dari bahagian hak milik rumah yang perlu difaraidkan akan menyebabkan ahli keluarga perlu berpindah dari rumahnya bagi menyelesaikan pembahagian pusaka ke atas sebahagian dari hak milik rumah tersebut.

\section{Harta Penamaan (Nomination) Wang Simpanan Pekerja}

Penamaan atau Nominee merupakan suatu kontrak pemindahan harta semasa yang tertakluk di bawah perundangan memerlukan kepada penilitian serta pemahaman yang konkrit terhadap kedudukannya dalam perundangan dan kesesuainnya dengan hukum syariat.

Fatwa MUIS tahun $1971^{6}$ dan fatwa tahun 1978 di Malaysia, ${ }^{7}$ kedua-dua jawatankuasa fatwa memutuskan bahawa Penama (Nominee) hanya dianggap 
sebagai Wasi atau pengamanah yang mana apabila menerima wang tersebut perlu mengembalikan hartanya kepada ahli waris untuk dibahagikan secara faraid dan bukan sebagai pewaris mutlak sepertimana yang difahami dalam perundangan sivil. ${ }^{8}$

Pertembungan undang-undang dan hukum Islam dalam masalah ini dapat dilihat dalam kes Saniah Ali lwn Abdullah Ali, kes ini melibatkan dua jumlah iaitu $\$ 8.038 .76$ dan $\$ 60,607.71$ yang dikeluarkan melalui Wang Simpanan Pekerja (CPF) si mati Salleh bin Ali. Plantif yang merupakan kakak tiri kepada si mati memohon kepada mahkamah bagi menjelaskan kedudukan wang yang diperolehi secara penamaan melalui bayaran langsung oleh Badan CPF kepada beliau. Dalam kes ini juga, defenden yang merupakan adik beradik lelaki kandung menuntut agar wang yang dipindahkan secara nominasi agar dibahagikan mengikut seksyen 111, 112 \& 115 AMLA yang menjelaskan bahawa segala pusaka orang Islam dibahagikan mengikut hukum Islam. Defenden juga mengemukakan sijil pusaka yang dimohon melalui Mahkamah Syariah dalam menentukan ahli waris yang berhak mewarisi pusaka si mati. Jumlah pertama yang telah dibayar oleh Dana Wang Simpanan Pekerja telah dipersetajui bahawa ianya merupakan milik defendan. Perselisihan yang berlaku adalah ke atas jumlah kedua sama ada ianya tertakluk di bawah Akta CPF atau Akta AMLA. Peguam bagi pihak defendan turut mengemukakan keterangan fatwa berkenaan pandangan hukum Islam tentang penamaan ini melalui surat yang dikemukakan oleh pihak peguam kepada Majlis Ugama Islam. Hakim Mahkamah Tinggi berpandangan bahawa fatwa hanya merupakan pandangan Majlis dan Mahkamah tidak terikat kepadanya dan perkara yang berbangkit dalam kes ini adalah pihak manakah yang berhak ke atas wang yang dibayar disebabkan kematian seorang muslim di Singapura berpandukan kepada Akta CPF dan AMLA dan bukan undang-undang Islam. Hakim berpandangan dan memutuskan bahawa wang yang berjumlah $\$ 60,607.71$ bukan sebahagian daripada harta pusaka si mati dan tidak tertakluk di bawah seksyen 112(1) AMLA. Plantif iaitu Saniah Ali berhak ke atas kesemua wang yang dibayar oleh Badan CPF berdasarkan kepada Akta CPF. Hasil daripada itu, keputusan ini telah menyebabkan pertembungan antara fatwa yang diputuskan pada tahun 1971 dengan ketetapan undang-undang itu sendiri (Saniah Ali lwn Abdullah Ali [1990] SLR 584-593.).

\section{Hasil Wang Insurans}

Di Singapura, perkara yang melibatkan insurans termasuk takaful tertakluk di bawah peruntukan yang tersendiri bagi mengawal segala transaksi urusniaga yang dikenali Akta Insurans tahun 2002. ${ }^{9}$ Pemilikan Insurans dan takaful adalah sebahagian dari harta yang dimiliki hasil dari pembelian dari syarikat-syarikat insurans yang menawarkan pelbagai jenis insurans bagi membantu kos kehidupan 
lain seperti kos kesihatan, kos pelayaran luar negeri, kos kenderaan dan beberapa kos lain yang memerlukan pembelanjaan yang tinggi tanpa insurans.

Pertimbangan yang perlu diambil kira adalah kedudukannya sama ada diterima sebagai salah satu bentuk pusaka yang halal diwarisi atau tidak. Dalam hal ini, para fuqaha berbeza pendapat tentang keharusan harta insurans yang turut memberi kesan kepada pemilikannya sebagai sebuah aset yang diakui syarak. Majoriti para ulamak mengharamkan kontrak insuran tertamanya insurans hayat kerana unsur urusniaga yang tidak diketahui (Jahalah), riba, perjudian (Maysir) dan tidak pasti (Gharar) dalam insurans konvesional (Al-Basyir, 2002: 4). Bagi para ulamak yang mengharuskan kontrak insurans berhujjah atas dasar keperluan dalam kehidupan, keperluan dapat mengatasi sesuatu unsur penipuan atau tidak pasti dan mengambil kira kaedah fiqh "Asal sesuatu diharuskan kecuali ada dalil yang mengharamkannya" (al-Darir, 1990: 653).

Sekiranya diteliti kepada yang dikeluarkan fatwa di Singapura, Jawatankuasa fatwa MUIS tahun 1988 telah memutuskan masyarakat Islam diberikan kebebasan untuk memilih pandangan ulamak dengan mengambil kira tahap keperluan mereka kepada insurans. ${ }^{10}$

Dengan itu, selagimana sesuatu insurans yang merupakan kontrak terkini dalam pasaran tidak memiliki empat unsur yang dinyatakan di atas dan mendapati keperluan kepadanya, insurans diharuskan dari sudut syarak dan menjadi sebahagian dari harta (Al-Zarqa', 1994: 91). Selain itu juga, Takaful turut ditawarkan di Singapura oleh syarikat HSBC, syarikat ini menawarkan pelbagai produk seperti pelan takaful perlindungan keluarga, perlindungan rumah, perlindungan kenderaan, Takaful pakej Umrah dan Takaful pakej Masjid (Barrister Binta Kabir Isa \& Kabiru Isa Dandago, 2010: 9). Namun pasaran takaful di Singapura masih rendah dan hanya menyumbang kepada satu peratus dalam pasaran Insurans sedunia. ${ }^{11}$

\section{Pengabaian Fatwa oleh Pihak Mahkamah Sivil}

Dalam Seksyen 32 Akta AMLA menyatakan bahawa mana-mana pihak termasuk mahkamah boleh membuat permohonan kepada Majlis Ugama bagi mendapatkan fatwa dalam perkara yang berhubungkait dengan undang-undang Islam. Namun, melihat kepada kes-kes yang dibincangkan lalu didapati bahawa mahkamah telah menolak fatwa-fatwa yang dikemukakan sebagai sebahagian daripada bukti-bukti yang diketengahkan semasa perbicaraan dalam kes yang melibatkan harta pusaka orang Islam di Singapura. Hal ini berlaku disebabkan fakta yang dikemukakan tidak sama sekali secara logiknya dapat dipertahankan dan ia tidak selari dengan undang-undang berpandukan kepada intrepertasi mahkamah serta berlawanan dengan dasar keadilan dan kesaksamaan (Aidil Zulkifli, 2009: 3-4). 
Ini dapat dilihat dalam kes Mohamed Ismail bin Ibrahim and Another $v$ Mohammad Taha bin Ibrahim. Dalam kes ini terdapat wasiat yang menetapkan bahawa pusaka perlu dibahagikan tiga bahagian dengan 1/3 dari bahagian itu hendaklah dibahagikan mengikut kaedah nuzriah. Konsep Nuzriah merupakan sebahagian dari bentuk nazar bersyarat 'Nadhar Mu'allaq' dengan nazarnya itu diberikan kepada sebahagian ahli keluarga dan menjadi amalan sebahagian penduduk kampung di Yaman dari kalangan Mazhab Syafii. Perlaksanaan nazar dapat ditetapkan kepada 3 hari atau sejam sebelum kematian penazar (Al-Syatiri, Muhammad bin Ahmad, 1997: 433-435; Ba'alwi, 'Abd al-Rahman bin Muhammad bin Husyayn bin 'Umar al-Mahsyur, t. th.: 305 \& 307). Persoalan yang timbul adalah kebenaran seorang muslim melakukan nazar ke atas hartanya di Singapura. Peguam defendan telah memohon kepada Jawatankuasa Fatwa berkenaan persoalan nuzriah yang diwasiatkan itu. Salinan fatwa yang memperakui kesahihah nuzriah telah diberikan kepada peguam plantif. Fatwa bertarikh 1 Jun 1999 menyatakan bahawa nuzriah bukannya wasiat sebagai jawapan kepada pertanyaan firman guaman Mallal \& Namazie berkenaan nuzriah. Oleh kerana itu, pemberian atas dasar nuzriah tidak ada had maksimum dan boleh diberikan kepada orang yang sama serta tidak melanggar undangundang Islam. Begitu juga dalam fatwa sebelumnya yang dikeluarkan pada 3 Ogos 1998 menjelaskan bahawa nuzriah adalah akad yang sah dan masih berkuatkuasa walaupun pihak-pihak yang diberikan pemberian tersebut menafikan haknya ke atas bahagian nuzriah tersebut. Pada 5 April 2002, Tuan Haji Maarof Salleh, Presiden MUIS ketika itu turut mengeluarkan surat pengesahan ke atas segmen nuzriah dalam kes ini. Namun, plantif menolak keputusan serta pandangan berkenaan nuzriah dan berpandangan bahagian yang ditetapkan secara nuzriah perlu dibahagikan mengikut hukum faraid. Setelah mendengar hujah serta bukti-bukti yang dikemukakan semasa perbicaraan, mahkamah mendapati bahawa penetapan untuk melaksakan nuzriah itu terbatal, tidak semua ilmuwan membenarkan nuzriah kepada anak-anak dan tiada sebarang persetujuan dikalangan ilmuwan tentang keharusan nuzriah ini. Mahkamah memutuskan bahawa nuzriah adalah sedikit sebanyak sama dengan wasiat untuk diberikan kepada ahli waris yang tidak dibenarkan dalam hukum Islam. Dengan itu, bahagian yang telah ditetapkan sebagai nuzriah perlu dibahagikan kepada ahli waris yang berhak sepertimana yang ditentukan dalam sijil pusaka yang dikeluarkan oleh Mahkamah Syariah (Mohamed Ismail bin Ibrahim and another $v$. Mohammad Taha bin Ibrahim [2004] 4 SLR 756-783).

Dari satu sudut, mahkamah mengambil kira hukum Islam sepertimana yang ditetapkan dalam seksyen 114 AMLA. Namun, peranan fatwa dalam masalah ini turut mendapat tamparan disebabkan hujah yang dianggap tidak kukuh oleh mahkamah. 


\section{Perancangan Harta yang Tidak Kemas}

Para pemikir Islam dan pengkaji masa kini telah mengemukakan pelbagai perbincangan dan huraian kepada permasalahan yang wujud dengan mengemukakan beberapa cadangan dalam menyelesaikan permasalahan tersebut. Di Singapura, jawatankuasa fatwa dan beberapa agensi perancangan harta telah berusaha untuk menyelesaikan isu-isu yang wujud. Isu dapat diselesaikan dari satu sudut kemaslahatan ahli keluarga tetapi terdapat beberapa perkara lain juga turut wujud di dalam membuat perancangan dan kaedah tuntutan harta pusaka.

Hal ini dapat dilihat dalam kes yang berlarutan dalam pembahagian harta pusaka Gedung Kuning keluarga Al-Marhum Haji Yusoff Haji Mohd Noor, AlMarhum telah melantik dua pengamanah melalui wasiat untuk membahagikan harta kepada 11 orang ahli waris termasuk 16 orang cucu tersenarai dalam wasiat tersebut. Pada tahun 2000, perkara ini telah dibawa ke jawatankuasa fatwa dan diputuskan bahawa wasiat tersebut terbatal dan harta perlu dibahagikan secara faraid. Menurut cicit kepada Al-Marhum iaitu Hidayah Amin, sebelum perkara tersebut di bawa ke Jawtankuasa Fatwa, pengamanah bagi wasiat tersebut iaitu Zhukeflee Ismail telah berjanji akan mematuhi keputusan fatwa. Namun, pengamanah tidak dapat memenuhi keputusan tersebut kerana sewaktu ahli waris mengemukakan persoalan kepada Jawatankuasa fatwa, ia tidak dijelaskan sepenuhnya dalam perkara yang berhubungkait dengannya dan masih lagi terdapat beberapa persoalan belum terjawab oleh Jawatankuasa Fatwa. Menurut beliau juga, keputusan yang dikeluarkan adalah keputusan majoriti dan masih terdapat pandangan yang membantah pandangan yang dikeluarkan oleh Jawatankuasa Fatwa. Disamping itu, pengamanah berpandangan bahawa wasiat itu tetap sah dan tetap berpegang amanah wasiat itu kerana ahli waris tidak membantah wasiat tersebut sewaktu pembahagian sebahagian dari harta pusaka sebanyak $\$ 176,800$ yang telah dibahagikan sebelum ini, ini menunjukkan bahawa ahli waris yang berhak telah merelakan wasiat tersebut. ${ }^{12}$ Anggapan pengamanah terhadap reaksi ahli waris yang tidak membantah ketetapan wasiat merupakan petanda kerelaan ahli waris tidak seharusnya berlaku. Ini kerana diam ahli waris itu tidak membawa kepada persetujuan oleh mereka seperti yang dinyatakan dalam kaedah tidak dinisbahkan bagi diam itu kata-kata "لا ينسب للساكت قول" (AlSuyuti, Jalal al-Din 'Abd al-Rahman, 1997: 233). Dalam masa yang sama, ketetapan wasiat sebanyak $1 / 3$ hanya dilihat dari sudut had yang diperundangkan dalam seksyen 111(1) AMLA dan dilihat tidak menjejaskan segala wasiat yang telah ditetapkan sebelum penggubalan kepada Akta tersebut yang menyatakan: "Notwithstanding anything in the provisions of the English law or in any other written law, no Muslim domiciled in Singapore shall, after 1st July 1968, dispose of his property by will, or by any nomination under section 49M(2) of the Insurance Act (Cap. 142), except in accordance with the provisions of and subject to the restrictions imposed by the school of 
Muslim law professed by him." Ini menyebabkan batasan yang ditetapkan sebanyak $1 / 3$ wasiat dalam syarak tidak diambilkira, ini bertentangan dengan hadis Rasulullah s.a.w. yang diriwayatkan oleh Ibn Abbas r.a.berkata:

$$
\text { لو غضّ الناس إلى الربع لأن رسول الله صلى الله عليه وسلم قال: الثلث، والثلث كثير }
$$

Yang bermaksud: "Kalaulah Manusia mengurangi wasiatnya (dari 1/3) kepada 1/4, kerana Rasulullah s.a.w. bersabda: Boleh sepertiga dan sepertiga pun banyak." (AlBukhari, 2002, h. 677)

Ketetapan sepertiga ini juga turut dibahaskan dalam kes yang melibatkan wasiat peninggalan Sultan Johor ke atas hartanya Tyersall yang dijadikan sebahagian dari harta negara setelah kemangkatan Baginda dan bukan sebagai pusaka. Perbicaraan ini berlangsung di Mahkamah Tinggi Singapura antara State of Johor and another v. Tunku Alam Shah Ibni Tunku Abdul Rahman and Others. Menurut pihak Plantif, wasiat yang ditinggalkan oleh Sultan Abu Bakar tidak dikuasai di bawah perundangan Johor tetapi termaktub di bawah undang-undang Inggeris sepertimana yang diaplikasikan di dalam Koloni Singapura pada tahun 1895. Kesan kepada wasiat bagi harta yang tidak alih dikuasai secara khas melalui lex situs dan bukan lex domicile. Wasiat tersebut tetap sah sama ada berlawanan dengan hukum Islam ataupun tidak. Ini kerana pembahagian melalui wasiat bukan sebahagian dari lex situs pada 1895.

Defenden membuat tuntutan bahagian daripada pampasan yang diberikan ke atas pemgambilalihan Singapura ke atas Hartanah Tyersall. Menurut Defenden lagi, harta tersebut merupakan sebahagian dari pusaka yang perlu dibahagikan mengikut hukum Islam dan bukan sebahagian dari harta negara yang diwasiatkan oleh Sultan Abu Bakar. Wasiat tersebut dianggap terbatal dan berlawanan dengan hukum Islam.

Di dalam Mahkamah juga turut diperjelaskan kedudukan undang-undang AMLA bagi wasiat orang Islam di Singapura yang menghadkan wasiat berpandukan hukum Islam hanya berkuatkuasa pada tahun 1968 dan Akta tersebut tidak memberi kesan kepada orang Islam Singapura yang meninggal dunia sebelum 1 Julai 1968. Apabila membuat perbandingan antara AMLA dan Muslim Ordinance 1958, tiada sebarang larangan dikenakan ke atas seorang muslim yang menetap di Singapura dalam menentukan wasiatnya. Ini dapat dilihat dengan kesan perundangan Inggeris ke negeri-negeri selat turut mengesahkan kedudukan wasiat orang Islam kes Sheriffa Fatimah yang didapati tiada sebarang ketiadakadilan dalam wasiat yang ditetapkan olehnya.

Wasiat tersebut dilihat sah kerana Sultan Abu Bakar telah menetapkan keinginannya untuk menjadikan Tyersall adalah jelas. Ini kerana, Baginda juga turut menetapkan beberapa hartanya dibahagikan untuk isterinya dan selainnya dibahagikan kepada ahli warisnya. Dalam hal ini, niatnya agar Tyersall bukan lagi 
sebahagian daripada harta peribadinya selepas kemangkatannya dan dijadikan sebahagian dari harta negara adalah jelas.

Dengan itu, Mahkamah memutuskan bahawa pampasan sebanyak SGD25 juta berhak diberikan kepada pihak Plantif kedua hasil dari pengambilalihan ke atas Tyersall dan tidak boleh dirayu oleh pihak defenden (State of Johor and another $v$. Tunku Alam Shah Ibni Tunku Abdul Rahman and Others.[2005] 4 SLR 380-397).

\section{Kesedaran Hukum Pusaka Islam yang Rendah}

Keadaan ini sering kali berlaku ke atas ahli keluarga yang tidak memahami hukum syarak dengan sebaiknya sehingga lebih mementingkan keutamaan individu berbanding kebajikan ahli keluarga. Di antara aspek yang ketara dalam permasalahan ini adalah sewaktu fatwa belum diputuskan penama (Nominee) sebagai penerima secara mutlak, terdapat sebuah kes antara isteri dan ibu tiri kepada anak al-Marhum Zainab dan anak al-Marhum Melati Bte Ahmad. AlMarhum yang sememangnya mengambil berat tentang kebajikan anak-anaknya dan isterinya dengan al-Marhum telah membuat nominasi wang simpanan pekerja (CPF) untuk dibahagikan secara sama rata kepada ahli keluarganya setelah beliau meninggal dunia. Dalam kenyataan di atas, fatwa tahun 1971 menjelaskan bahawa penama (Nominee) hanya merupakan pengamanah sahaja dan wang CPF yang diperolehi perlu dibahagikan secara faraid dengan diselesaikan dahulu hak-hak bagi si mati dan membahagikan baki harta secara faraid dan adik beradik alMarhum juga merupakan ahli waris yang berhak menerima harta. Melati telah cuba berbincang dengan ibu tirinya berkenaan perkara ini akan tetapi ibu tirinya berpandangan bahawa wang itu telah sah menjadi milik mereka, adik beradik si mati tidak pernah mengambil berat tentang si mati dan sekaligus tidak perlu membincangkan soal pusaka dengan mereka. ${ }^{13}$ Selain dari kegagalan salah seorang penama membahagikan sebahagian hak kepada ahli waris yang lain, penama juga gagal dalam memastikan hak-hak si mati telah diselesaikan (Barraj, 1981: 91-93; Al-Bukhari, 2002: 308).

Dalam kes yang lain, adik-beradik al-Marhum Ahmad menuntut harta yang telah dihibahkan kepada si isteri oleh suaminya (Ahmad) melalui instrumen Hibah Ruqba. Perkara ini timbul disebabkan adik-beradik si mati tidak berpuashati ke atas jumlah pusaka yang diperolehi dari sebahagian harta si mati. Adikberadiknya mendakwa mereka memperjuangkan hak ayah mereka yang sakit memerlukan wang yang banyak untuk menampung kos perubatannya dan almarhum dikatakan jarang memberi sumbangan kepada ayah mereka kecuali didesak. ${ }^{14}$ Namun pemakaian instrumen Hibah dalam perancangan pusaka si mati seharusnya tiada sebarang tuntutan harus dipertikaikan. Ini kerana harta yang dihibahkan menyebabkan harta tersebut bukan lagi sebahagian dari pusaka si mati (Abdul Karim Ali, Raihanah Azahari, Ridzwan Ahmad, Muhamad Safiri 
Ismail \& Ameer Azeezy, 2006: 531). Tuntutan ke atas hak pusaka tidak dilarang oleh syarak tetapi sekiranya terdapat unsur paksaan atau sesuatu yang berlawanan dengan syarak adalah sesuatu yang dilarang. Di dalam masalah ini, tuntutan yang dibuat adalah cara paksaan ke atas harta yang tidak wujud sebarang pertikaan kerana telah dipindah milik secara Hibah Ruqba. Dalam masa yang sama, ahli waris telah diperjelaskan kedudukan harta si mati dari sudut perundangan sivil dan hukum Islam tetapi kerana perasaan tidak puas hati wujud mengakibatkan tuntutan yang tidak diingini berlaku. ${ }^{15}$

Dalam kes yang dikongsi di dalam akhbar pula, penulis menjelaskan kisah ibu dan bapa angkat yang dipaksa keluar dari rumah anak angkat mereka oleh ibu bapa kandungnya sendiri setelah mendapat tahu hak mereka dalam mewarisi pusaka anak mereka Linda yang dijaga oleh ibu bapa angkatnya Safiah dan Azman yang mana Ibu angkatnya merupakan kakak kepada Ibu kandungnya. Ibu bapa angkatnya telah ke Mahkamah Syariah untuk membuat permohonan sijil warisan dan menerangkan kedudukan mereka yang sebenar sebagai keluarga angkat kepada al-Marhumah. Pihak mahkamah menjelaskan bahawa mereka tidak mempunyai bahagian dalam pusaka kerana mereka berdua hanya keluarga angkat kepada si mati. Nora mengarahkan ibu dan bapa angkat untuk keluar dari rumah tersebut dalam masa sebulan tanpa sebarang ihsan terhadap jasa keduadua mereka membesarkan anak kepada Nora. ${ }^{16}$

Dalam aduan lain yang turut mengambarkan kelemahan keluarga Islam dalam masalah pusaka ini seperti yang dikhabarkan dalam berita tuntutan pusaka si mati antara Alina isteri kepada Al-Marhum dan adik beradik Al-Marhum.. Alina telah melaporkan bahawa tuntutan yang dibuat oleh adik-beradik AlMarhum tidak bersifat ihsan ke atas dirinya yang dijangkiti penyakit HIV hasil jangkitan daripada al-Marhum. Abang kepada al-Marhum dan juga selaku pengamanah ke atas harta pusakanya mendakwa bahawa al-Marhum ketika sakitnya pernah memberitahu kepada abangnya bahawa beliau ingin meletak nama abangnya itu sebagai pemilik rumah tersebut tetapi tidak berlaku kerana abangnya mempunyai rumah lain tetapi disangkal oleh Alina kerana hal sebenar yang berlaku adalah suaminya ingin meletak namanya sebagai pemilik bersama rumah tersebut. Adik-beradiknya juga mendakwa Alina tidak berlaku adil dengan tidak memberikan hak mereka yang sepatutnya dan Alina juga telah mengeluarkan nama adik-beradik al-Marhum daripada sijil warisan atas nasihat penguamnya. Hasil dari jangkitan tersebut, beliau telah membuat tuntutan ganti rugi di Mahkamah Tinggi disebakan kegagalan si mati memaklumkan lebih awal penyakitnya dan kehilangan mata pencarian disebabkan jangkitan tersebut untuk membesarkan anak-anaknya dari hasil perkahwinan terdahulu. ${ }^{17}$ Ini sekaligus merupakan suatu usaha bagi menafikan hak ahli waris dan menghasilkan permasalahan kepada pembahagian harta pusaka secara faraid, hasilnya dari itu kemudaratan cuba diatasi dengan kemudaratan lain dengan penafian hak ahli 
waris disebabkan jangkitan yang dialami olehnya, perkara ini tidak seharusnya berlaku kerana kemudaratan tidak terhilang dengan kemudaratan الضرر لا يزال" " بالضرر seperti yang dinyatakan oleh Ibn al-Subki: Kemudaratan hilang tetapi tidak dengan kemudaratan (Al-Suyuti, 1997: 143).

Dari kes-kes yang dinyatakan menunjukkan kelemahan ahli waris dalam memahami hukum pusaka dan kuasa mereka dalam membuat tuntutan. Hak yang layak diwarisi seharusnya mengambil kira juga panduan umum dan etika pewarisan. Malahan Islam turut menggalakkan perkongsian sebahagian dari hak yang dimiliki dengan diberikan kepada mereka yang tidak mewarisi. Budaya seperti ini yang seharusnya diterapkan dalam menyelesaikan pembahagian harta pusaka di Singapura.

\section{Peranan Badan-Badan Islam dalam Pembahagian Harta Pusaka Islam di Singapura}

Dalam melihat kepada permasalahan yang dibincangkan di atas, terdapat usaha bagi memperbetulkan perlaksanaan hukum Islam di Singapura. Badan-badan kerajaan seperti MUIS dan Mahkamah Syariah atau badan-badan bukan kerajaan (NGOs) seperti Persatuan Ulamak dan Guru Agama Islam Singapura (PERGAS) dan syarikat swasta seperti Barakah Capital dan Syarikat HTHT menawarkan khidmat nasihat kepada masyarakat Islam Singapura dan berusaha memberi pendedahan yang jelas dan panduan dalam menyelesaikan permasalahan yang berhubungkait dengan pembahagian harta pusaka.

Majlis Ugama Islam Singapura sebagai badan berkanun senantiasa menitik berat kepada isu yang dihadapi di dalam masyarakat dengan membuat kajian yang serius kepada isu-isu yang wujud dan menyelesaikannya secara perbincangan melalui saluran fatwa atau Irsyad (Panduan) yang dikeluarkan oleh Pejabat Mufti di MUIS. Majlis Ugama Islam Singapura juga turut menyediakan khidmat konsultasi untuk masyarakat Islam yang ingin mendapatkan nasihat agama berkenaan pembahagian harta pusaka secara Islam.

Di antara usaha-usaha yang telah dijalankan oleh MUIS dan Mahkamah Syariah seperti penyediaan risalah ringkas dwibahasa (Bahasa Melayu \& Inggeris) yang mudah difahami bagi memudahkan masyarakat Islam memahami sedikit sebanyak berkenaan hukum faraid secara asas dengan diselitkan soalan-soalan lazim berkenaan pusaka dan peranan MUIS sebagai Pentadbir Baitul Mal bagi harta-harta yang tidak diwarisi. Dalam usaha lain yang memberi kesan dalam menghuraikan isu pembahagian harta di Singapura adalah fatwa berkenaan perumahan 'Joint Tenancy' pada tahun 2008, fatwa penamaan (Nomination) Wang Simpanan Pekerja (CPF) pada tahun 2010 dan fatwa penamaan (Nomination) 'Revocable' dan 'Irrevocable' tahun 2012. Selain itu juga, MUIS telah berusaha mengadakan sesi pendidikan awam di beberapa masjid di Singapura bagi 
menjelaskan fatwa yang dikeluarkan sebagai usaha memberikan penjelasan dan kefahaman kepada masyarakat Islam terhadap fatwa-fatwa yang dikeluarkan itu. Dalam masa yang sama, fatwa ini turut dikongsi bersama dalam Majlis Muzakarah Ulama MABIMS tahun 2010 dan mendapat respon yang positif dari pembentangan fatwa dalam masalah harta pusaka di Singapura, respon positif turut diterima dari Menteri Bertanggungjawab Bagi Hal Ehwal Masyarakat Islam, beliau sangat mengalu-alukan fatwa tersebut dalam menyelesaikan isu-isu yang sekian lama wujud dalam masyarakat Islam di Singapura. ${ }^{18}$

Masjid-masjid di Singapura turut memainkan peranan mereka seperti Masjid Ar-Raudhah di Bukit Batok menawarkan khidmat nasihat faraid kepada jemaah, Masjid Assyakirin mengadakan kursus khusus berkenaan dengan Faraid dan Masjid Assyafaah mengadakan forum berkenaan dengan Faraid. Ini dapat dilihat melalui usaha-usaha pihak masjid serata Singapura sentiasa berusaha mengadakan program-program sebegini bagi membantu masyarakat Islam Singapura sedikit sebanyak mempunyai maklumat berkenaan hukum Faraid.

Bagi badan bukan kerajaan seperti PERGAS yang merupakan sebuah persatuan dan medan guru-guru agama berkumpul, berdiskusi dan mencurahkan bakti dalam dakwah Islam turut mengambil berat dengan suasana masyarakat yang mempunyai pelbagai persoalan dalam pembahagian harta pusaka dalam Islam. Persatuan ini telah membuat keputusan dengan menubuhkan sebuah unit yang dikenali sebagai Unit Konsultan Kewangan Islam (UKKI) yang memberi perhatian khusus kepada bidang harta pusaka di Singapura.

Syarikat-syarikat swasta juga turut memainkan peranan yang besar dalam mendidik masyarakat tentang harta pusaka dengan menyediakan khidmat konsultasi, kursus perancangan harta dan pusaka, penyediaan surat wasiat dan lain-lain serta menganjurkan seminar dan syarahan harta pusaka, penulisan di akhbar serta penghuraian masalah harta pusaka di Singapura melalui penulisan buku dengan kerjasama pensyarah dari IIUM Dr. Ismail Mohd @ Abu Hassan yang diterbitkan oleh syarikat HTHT Advisory Service di Singapura. ${ }^{19}$

Selain dari syarikat HTHT yang telah menjalankan usaha-usaha kerjasama dengan mendapatkan kepakaran dari kalangan pengkaji ilmiah, sebuah lagi syarikat komersial yang dikenali sebagai Barakah Capital yang dimiliki oleh Encik Suhaimi Salleh telah memberikan banyak sumbangan dari sudut perkongsian pengalamannya dalam sesi konsultasi yang dikendalikan oleh syarikatnya. Syarikat ini juga turut menganjurkan beberapa seminar dengan kerjasama beberapa syarikat lain dan badan-badan tertentu dalam memberikan pendidikan awam sepertimana penganjuran seminar pada tahun 2011 yang bertajuk Seminar Wasiat, Faraidh \& Rancang Pusaka dalam usaha menjelaskan perkara yang berkaitan dengan pusaka. ${ }^{20}$

Dengan perkembangan di atas dapat dilihat bahawa pelbagai usaha telah dijalankan dari sejumlah organisasi yang terlibat sama ada kerajaan dan swasta 
bagi menyampaikan maklumat yang diperlukan dalam pembahagian harta pusaka.

\section{Kesimpulan}

Pada asasnya undang-undang pusaka Islam telah mempunyai kedudukan yang agak selesa dalam perundangan Singapura. Walaubagaimanapun terdapat beberapa masalah dari segi pelaksanaannya seperti beberapa halangan perundangan, kuasa mahkamah sivil serta polisi yang sedikit sebanyak mengganggu pelaksanaan sepenuhnya undang-undang Islam tersebut. Permasalahan lain timbul disebabkan kefahaman yang rendah dalam kalangan masyarakat Islam Singapura sendiri. Dalam hal ini, MUIS dan beberapa badan bukan kerajaan (NGOs) serta syarikat-syarikat swasta perlu lebih bergiat aktif dalam usaha mengadakan pelbagai khidmat dan program bagi meningkatkan lagi kefahaman masyarakat Islam tentang hukum pusaka Islam sesuai dengan konteks Singapura. Dengan itu, penerimaan Undang-undang Islam untuk diamalkan dalam pentadbiran hukum Islam secara khusus untuk masyarakat Islam di Singapura sebagai undang-undang diri dalam persoalan pusaka Islam perlu dimanfaatkan dan dipelihara dengan sebaiknya.

\section{Notahujung}

\footnotetext{
${ }^{1}$ Lihat, Legislation History: Administration of Muslim Law Act (Cap. 3).

${ }^{2}$ Ibid.

${ }^{3}$ Sect. 7, Intestate Succession Act (Cap. 146); Lihat juga, 6(e), Distribution Act 1958 (Act 300).

${ }^{4}$ Lihat, Sect. 7(1)(d), Estate Duty Act (Cap. 96); Sect. 53(5), Land Titles Act (Cap. 157); Sect. 66(a)(3)(a), Conveyancing and Law Property Act, (Cap. 61).

${ }^{5}$ Pemilik syarikat HTHT Advisory Service yang memberikan khidmat nasihat kewangan dan pusaka Islam di Singapura.

${ }^{6}$ Kumpulan Fatwa MUIS, Wang Simpanan Pekerja, bertarikh 30 Oktober 1971.

7 Keputusan Jawatankuasa Fatwa Majlis Kebangsaan Bagi Hal Ehwal Ugama Islam Malaysia Kali Ke-15, Penamaan Wang KWSP, bertarikh 6 Mac 1978.

${ }^{8}$ Sect. 25, Central Provident Fund Act (Cap. 36).

9 Sect. 3 (1), Insurance Act (Cap. 142).

${ }^{10}$ Keputusan Fatwa MUIS, 'Insurans Berkumpulan', bertarikh 24 Ogos 1988.

${ }^{11}$ Dipetik dari kenyataan Akhbar Channel News Asia pada 9 March 2010 yang bertajuk 'Takaful Market Poised for Growth but Lacks Shariah Compliant Investments, Talent'.

12 Akhbar Berita Harian bertarikh 10 Januari 2010 yang bertajuk 'Gedung Kuning dalam Kemelut Undang-undang'; Lihat juga, Affidavit in Originating Summons 60 of 2002/F in the High Court of Singapore.
} 
${ }^{13}$ Akhbar Berita Harian bertarikh 16 Ogos 2009 yang bertajuk 'Wang CPF Si Mati Haruskah Ikut Faraid?'.

${ }^{14}$ Akhbar Berita Harian bertarikh 20 September 2010 yang bertajuk 'Hibah Flat, Wang CPF Arwah Suami Kepada Isteri Ditikai Adik-beradik'.

${ }^{15}$ Akhbar Berita Harian bertarikh 20 September 2010 yang bertajuk'Tuntut 'Hak' Sebab Tidak Puas Hati'.

16 Akhbar Berita Harian bertarikh 6 Disember 2009 yang bertajuk 'Harta Arwah Anak: Patutkah Ibu Bapa Dapat?'.

${ }^{17}$ Akhbar Berita Harian bertarikh 17 Mac 2010 yang bertajuk 'Flat Arwah Pesakit Aids Jadi Rebutan Janda dan Adik-beradik' dan Akhbar Berita Harian bertarikh 20 Mac 2010 yang bertajuk 'Nama Adik-beradik Dipotong dari Sijil Waris'.

18 Pembetangan dalam Majlis Muzakarah Ulama MABIMS 2010 oleh Timbalan Mufti Singapura, Dr. Mohd Fatris Bakaram pada 12 Oktober 2010.

19 Sebahagian dari karangan Sadali Rasban pemilik syarikat HTHT seperti Hibah al-Ruqba dan Joint Tenancy di dalam Hukum Syariat, Muslim law in Wealth and Estate Transfer, Dying Intetstate dan beberapa buah buku lain dengan kerjasama Dr. Ismail Mohd. HTHT Advisory Services, http://www.htht.com.sg/estate_planning_intro.php, Dikemaskini pada 10 Oktober 2010.

${ }^{20}$ Encik Suhaimi Salleh pemilik Barakah Capital turut merasmikan serta memasarkan buku kompilasi Makalahnya dalam Berita Harian berkenaan pusaka semasa seminar tersebut. Barakah Capital Planners, http://www.barakahcapital.com.sg/default.aspx?uc=3. Dikemaskini pada tahun 2012.

\section{Rujukan}

Al-Qur'an al-Karim.

'Abbas, Fadil Hassan \& 'Abbas, Sana' Hassan. (1991). I'Jaz al-Qur'an al-Karim, 'Amman: Dar al-Furqan, h. 322.

Abdul Karim Ali, Raihanah Azahari, Ridzwan Ahmad, Muhamad Safiri Ismail \& Ameer Azeezy. (2006). Produk Hibah dan kesannya kepada pencapaian Maqasid. Dalam Sistem kekeluargaan Islam di Malaysia dalam Maqasid alShariah and its realization in contemporary societes, 3. Kuala Lumpur: IIUM, h. 531.

Abshire, J. E. (2011). The history of Singapore. California: Greenwood, h. 25.

Ahmad Ibrahim. (1979). Development in the marriage laws in Singapore since 1959. Dalam Bashir Ahmad Mallal (Ed.), The Malayan Law Journal. Singapore: Malaya Publication House Ltd, h. 47.

Aidil Zulkifli. (2009). The fate of fatwa in Singapore. In Karyawan, 10:1:3-4, Singapore: Association of Muslim Professionals.

Al-Basyir, Taha Hasan 'Abd. (2002). A brief introduction to the Fiqh contemporary Shariah Compliant Finance, In Fifth Harvard Univesity, Forum on Islamic 
Finance, organised by Cambridge Centre For Middle Eastern Studies, Harvard University on 7 April 2002, h. 4.

al-Bukhari, Abi 'Abdillah Muhammad bin Ismail. (2002). Sahih al-Bukhari, Bab: alWasiyyah bi al-Thuluth, Kitab: al-Wasaya, Beirut: Dar Ibn Kathir, hadith no. 2743.

Sahih al-Bukhari, Bab: al-Kafnu min Jami' al-Mal, Kitab: al-Janaiz, Beirut: Dar Ibn Kathir, h. 308.

al-Darir, al-Sadiq Muhammad Al-Amin. (1990). al-Gharar wa Atharuhu fi al-‘Uqud fi al-Figh al-Islami: Dirasah Muqaranah. Beirut: Dar al-Jalil, h. 653.

al-Sabuni, Muhammad 'Ali. (1388H). al-Mawarith fi al-Syari'ah al-Islamiyyah, Beirut: Dar al-Kutub al-'Ilmiyyah, h. 49, 65 \& 68.

al-Suyuti, Jalal al-Din 'Abd al-Rahman. (1997). Al-Asybah wa al-Nazair, j. 1, c. 3, Riyadh: Maktabah Nazar Mustafa al-Baz, h. 143\& 233.

Al-Syatiri, Muhammad bin Ahmad. (1997). al-Yaqut al-Nafis, Beirut: Dar al-Hawi, h. $433-435$

al-Zarqa', Mustafa Ahmad. (1994). Nizam al-Ta'min: Haqiqah wa al-Ra'y al-Syar' i fih, Beirut: Mu'assasah al-Risalah, h. 91.

Ba'alwi, 'Abd al-Rahman bin Muhammad bin Husyayn bin 'Umar al-Mahsyur. (t.t.). Bughyah al-Mustarsyidin, S.1.: S.n., h. 305 \& 307.

Barakah Capital Planners. http://www.barakahcapital.com.sg/default.aspx?uc=3. Dikemaskini pada tahun 2012.

Barraj, Jum'ah Muhammad Muhammad. (1981). Ahkam al-Mirath fi al-Syari'ah alIslamiyyah, Amman: Dar al-Fikr Li Nasyr wa al-Tawzi', h. 91-93.

Barrister Binta Kabir Isa \& Kabiru Isa Dandago. (2010). “Promoting cooperative "Takaful" to commercial "Takaful" status for societal regeneration: A case study of A. A. Zubairu initiative". In 2nd International Conference on Islamic Economic and Trade Integration, Tehran, Iran, on 21-22 November 2010, h. 9.

Bouma, G. D. Bouma, Ling, Rod \& Pratt, Douglas. (2008). Religious diversity in Southeast Asia and the Pacific. New York: Springer, h. 99.

Evans, I. H. N. (1927). Ethnology and archaeology of the Malay Peninsula. Cambridge: Cambridge University Press, h. 43.

Hairani Saban. (2010). Report on the Muslim law practice committee round table: Implications of Shafeeg's case". In Law Gazatte, h. 21-23. Singapore: Lexis Nexis

Halijah Mohamad. (2011). Pemilikan Harta tidak boleh alih dan implikasinya ke atas perancangan harta pusaka orang Islam. Dalam Seminar Wasiat, Faraidh dan Rancang Harta Pusaka, Politeknik Singapura, Singapura pada 20 Februari 2011, h. 97. 
Hanizah Idris. (1997). Pulau Singapura, 1819-1930: Peranan pulau-pulau lain yang terpinggir di dalam sejarahnya." Jati: Journal of Southeast Asian Studies, 3, 71.

Hooker, M.B. (1983). Introduction: The translation of Islam in Southeast Asia. In (ed. Hooker, M.B.), Islam in South-east Asia, Laiden: E.J. Brill, h. 1-22.

HTHT Advisory Services. (2010). Dikemaskini pada 10 Oktober 2010. http://www.htht.com.sg/estate_planning_intro.php.

Kong, Lily \& Yeoh, B.S.A. (2003). The politics of landscape in Singapore: Construction of "nation". New York: Syracuse University Press, h. 77.

Lee, Edwin. (2008). Singapore: The unexpected nation. Singapore: ISEAS, h. 1.

Majlis Ugama Islam Singapura. (1991). Kumpulan Fatwa, j. 3, Singapura: Majlis Ugama Islam Singapura, h. 38.

Maria Khristina S. Manueli, Rodney C. Jubilado \& Hanafi Hussin. (2009). Translating religious and cultural concepts: Challenges in building a bilingual dictionary for Filipino and Malay. Jati: Journal of Southeast Asian Studies, 14, 41.

Perkins, Jane. (1984). Kampong Glam: Spirit of community. Singapore: Times Publisher, h. 8 .

Rahimin Affandi Abd Rahim, Ruzman Md Nor, Nor Hayati Md Dahlal \& Norafifah Abd Hamid. (2013). "Islam dan kearifan tempatan di alam Melayu: Analisi kritikal. Jati: Journal of Southeast Asian Studies, 18, 223-224.

Sadali Rasban. (2010). Hibah al-Ruqba E joint tenancy in Shari'ah law. Singapore: HTHT Advisory Service Pte. Ltd., h. 20-21.

Shafeeq bin Salim Talib \& Anor lwn Fatimah Bte Abud bin Talib \& Anor [2009] 3, SLR 439-451; [2010] 2, SLR 1123-1153.

Sharon Siddique. (1986). Administration of Islam in Singapore. In Sharon Siddique dan Taufik Abdullah (Eds.), Islam and Society in South-East Asia, Singapore: Institute of South-East Asia Studies, h. 315-326.

Shaharil Talib. (1995). Singapore (1824-1958): This is my island in the sun. Jati: Journal of Southeast Asian Studies, 1, 1-22.

Singapore Government. (1966). Select committee on the administration of Muslim law Bill, h. 1.

Singh, K. S. \& Wheatley, Paul. (1990). Management of success: The moulding of modern Singapore. Singapore: Institute of Southeast Asian Studies, h. 629.

State of Johor and another v. Tunku Alam Shah Ibni Tunku Abdul Rahman and Others [2005] 4, SLR 380-397.

Sussman, M. B., Cates, J. N. \& Smith, D. T. (1970). The family and inheritance, USA: Russel Sage Foundation, h. 16-17.

Tong, C.K. (2007). Rationalizing religion: Religious conversion, revivalism and competition in Singapore Society, Leiden: E.J. Brill, h. 49. 
Wan Zailan Kamaruddin Wan Ali, Ahmad Zuhdi Ismail \& Jasamad Han @ Phu Van Han. (2013). Masyarakat Muslim Melayu Cham di Vietnam: Kajian mengenai isu dan cabaran dalam pemikiran Islam era globalisasi. Jati: Journal of Southeast Asian Studies, 18, 132-133. 